\title{
Art and Education or Education through Art: Educating through Image
}

\author{
Peri Mesquida, Kellin Cristina Melchior Inocêncio \\ Post-Graduation Program of Education, Pontifical Catholic University of Paraná, Curitiba, Brazil \\ Email: mesquida.peri@gmail.com
}

Received 19 April 2016; accepted 17 June 2016; published 20 June 2016

Copyright (C) 2016 by authors and Scientific Research Publishing Inc.

This work is licensed under the Creative Commons Attribution International License (CC BY). http://creativecommons.org/licenses/by/4.0/

(c) (i) Open Access

\begin{abstract}
This article is part of a partial research report on education through art in preschool and elementary school, mainly in the last year of preschool and in the first year of primary school when the teachers start the process of children's literacy. After researching a bibliography about the subject, going from art teaching to its relevance in all levels of education, we focused our attention on imagery art not as scientific discipline teaching, but as a didactic/pedagogic way of educating and alphabetizing. In order to reach this result, researchers focused on the interpretative analysis of works about art/education mainly based on Read (1958), Barbosa (1994), to then explore the theoretical/practical thought of Freire $(2000,1992)$, which indicated the relevance of the imagery art use as a didactic/pedagogical way to the education/alphabetization of children.
\end{abstract}

\section{Keywords}

Art/Education, Art Teaching, Teaching Through Art, Paulo Freire Methodology

\section{Introduction}

We are able to see through the window of the classroom the evolution of constructive action of an ovenbird building its house in a branch of the araucaria tree. It took months to go from the land to the tree and from the tree to the land in a busy way, laying "bricks" made with its beak and sometimes kneading it with its feet. When the house was made, it nested with its match. Sometime later, there were babies and it was possible to see that the parents are now became educators teaching the building art to their children. They have certainly listened carefully to what they were told, and have also observed the house in order to reproduce it later. This would be, after all, their work of art—a work that would bring meaning to their existence. By leaving the nest, they probably looked at it carefully, memorizing the image in order to build their own house using their parents "teaching" and individual observation.

If it is through the interaction of the child with the environment in which he/she is in his and her learning 
starts, the ovenbird lesson to its babies symbolizes the contribution that art can give to education.

After all, art is something that involves us, and most of the times without letting us even realize it. Due to that fact, Herbert Edward Read writes in his work Education through Art (1958):

Art is one of those things that just like the oxygen and the soil are everywhere around us. We almost never think about it, though. That why art is not something that can be only found in museum and art galleries or in old cities like Florence and Rome. Art, regardless of how we define it, is present in everything we do to please the senses (Read, 1958: p. 2).

In Metaphysics, Aristotle (2005), Aristotle presents his philosophy as "first philosophy" and the way that philosophy works through reflection is known as "formal logic". Things make sense to us for their form, regardless of being sound, auditive or sensorial forms. Therefore the form of a work of art is for example, "the configuration that it took. It doesn't matter if it is a building, a statue, a picture, a sonata” (Read, 1958: p. 3), or either the way it happened with the ovenbird baby, the form that its parents' house took in its "mind".

According to the common sense that was established, the teacher needs to take a certain form in order to become an educator. That is the reason for course such as "teachers' formation" and even artistic education, with the purpose of forming "art-educators". They are going to work with something we could call aesthetic education which has as a goal, according to Read (1958, p. 22):

1. The preservation of the natural intensity of every form of perception; 2. The combination of the several forms of perception and sensation among themselves and related to the environment; 3 . The expression of feelings in a communicable way; 4 . The expression in a communicable way of several forms of mind experiences which, in some other way, would be partially or totally unconscious; 5 . The thought expression in the right way (1958, p. 22).

Therefore, the art-educator has a fundamental goal in his pedagogical action of providing means to the child to keep his perception capability of things around him, of coordinating that perception with the environment, expressing formally through the senses, touch, sight, hearing, and smell what touched his/her emotion in his/her relation with the environment. In that sense, education could be defined as the development of the forms of expression, meaning "teach children and adults how to make sound, images, movements, and tools. A person who is able to do those things well can be considered a well educated one" (Read, 1958: p. 24). While that child has this natural skill to discover, which according to Aristotle (2005, p. 184) needs to be developed with the help of an adult, either the parents, or the teachers, the absorption of the environment and its representative expression by the child develops in an "organized" way, having a result which also comes from pedagogical action.

\section{The Children and the Learning through Image}

Lino Macedo in his work Constructivist Essays (1994) uses Aphrodite and Hephaestus myth to draw a comparison between that myth and the building of forms and contents by the child. Aphrodite which is married to Hephaestus. He was lame and clumsy, and she was the goddess of love and beauty. Due to the fact she couldn't love men; she used and replaced them with the intention of making use of Love and beauty. That caused a terrible suffering to Hephaestus. He "built a net with his lover apron to imprison Aphrodite. It is told that the gods laughed at his fruitless illusion and that Aphrodite, which was elusive and ephemeral, moved on with her life of spreading beauty and love on all things, and carefully assured that nobody else could do that better than her" (Macedo, 1994: p. 7). Even by not being successful in imprisoning Aphrodite, according to the myth, Hephaestus became a famous artisan. He became an artist,

That happened because by trying to imprison he could internalize his "form", or better, its criteria. After that his challenge was: in each work overcome his weaknesses more and more, and even if it was in vain, he wanted to put in each work something to remind him of his goddess, or the image that Hephaestus had of her. He tried to make it visible in his work to every man (Macedo, 1994: p. 7).

Macedo even says that the artistic/handmade work of Hephaestus can be compared to the one that Piaget tells about the relevance of action schemes building to a child. He/She is born "lame" and "clumsy" in order to develop his/her relationship with the environment. That way, following Hephaestus' steps, the child should build the "schemes" of environment appropriation and his/her relationship with it in a way to understand it and get in- 
tegrated to it. He/She uses the imagination and the learning in a way to "design” the net and imprison the environment. He/She makes use of something that his/her imagination apprehended and his/her learning provided him/her in a way to meet his/her needs. The child is like that to Piaget (1986), imaginative and by being like thatbe creative. In that case, he/she is unlike the ovenbird baby that is unable to create something new, only repeats what was learned and memorized as an image in its mind.

By building forms and contents, the child develops actions that make it possible to absorb the object and its projection. In order to "build a form, it is necessary that the action contents creatively differ and multiply, making it possible to be assimilated as something new. The transformations of actions are secondary to their similarities to the object whose form is established as an image, tool, gesture, text, work of art” (Macedo, 1994: p. 9). That way, the child reproduces a form of content whose form he/she sees and understands as being a "new" equal, alike to the original form of that content. In order to build something as a content, "the child must take out from the several forms that express to him/her what is common, gives him/her consistency (logical or aesthetical), is observed from one form to the other" (Macedo, 1994: p. 9). We could say then, that the action of the art-educator will happen in a way of taking the child to produce new forms of the same content or reproducing the form in which the content presents itself to him/her. In the first case, the art-educator will stimulate the child's creativity; in the second case, he/she will interrupt the child's imagination possibility of self-developing and become the creation and expression engine to what's new.

The childhood education develops its pedagogical action with children that are between zero and five years old. It is a phase in life where the child is learning very fast to communicate with the environment, and therefore to Express himself/herself. The word childhood itself comes from the Latin word infans, which means the one that can't speak. In that phase in life, the human being is learning how to express, look for the language through which he/she will communicate with the environment, regardless of being oral or gestural languages, or written and/or imagery languages. The Italian philosopher Giorgio Agamben (2005) says in his book Childhood and history that "The Idea of a childhood as a pre-subjective "psychical substance" turns out to be a myth, just as the one of a pre-linguistic subject, and the childhood and language seems to refer one to another in a circle in which childhood is the origin of language and language is the origin of childhood” (2005, p. 59).

If Agamben is right in his statement about childhood and language, it is a human characteristic that starts to be built in this phase of existence since the human being will little by little learn how to express himself/herself by imitating the expressions from adults or of those who are around them. In that sense, the artistic expression, regardless of being corporal expression through gestures, or by the use of the related language in its culture reflects the imagery representations that it makes of the environment by reproducing it.

That way, the artistic education or the art teaching in schools is something that can not be ignored. Ana Mae Barbosa says in her book The Image in Art Teaching (1994)

There is some kind of art teaching revival in the United States, not thanks to the governmental action, but mainly to the influence of Getty Foundation, which was created by the patrimony of the pretoleum king that has been financing researches and art experiences in schools. As a result of those researches, art has been seen now in the United States as a more immediate way of developing the analysis and synthesis capability through the multiple methodological approaches of artistic appreciation associated to making conscious art. (Barbosa, 1994: p. 3)

The same author elucidates that in her personal point of view, "art is not only basic, it is fundamental in a developing country's education. Art is not an ornament. Art is cognition, a profession, a different form of word to interpret the world, the reality, the imaginary and it is also content. As content, art represents the best work of the human being." (1994, p. 4).

\section{Art and Education in Brazilian Educational Legislation}

In Brazil, the art teaching started to be part of the legislation only in 1971, in law n. 5.692. It was then included in the curriculum, but as artistic education. It was not a discipline to be taught, but an educational practice, or an "educational activity". Although it was that way, it was an advance in the way art teaching was considered then.

It was when it was possible to see the versatility of artistic expressions: dance, theater, music, fine arts, etc., and the need to prepare professionals which could work with that "educational activity". Those professionals would be prepared in "artistic education" courses as a teaching degree created by several higher education insti- 
tutions.

With the law n. 9.394/96, the previous provisions were suspended and art started to be considered mandatory in primary education: "Art teaching will be a mandatory curriculum component in several levels of primary education in order to promote the cultural development of students” (article 26, paragraph $2^{\circ}$ ). Therefore, it is not considered a "simple" activity, but the art teaching as a discipline. Even more, it started a discussion all over the country in higher education institutions and the Ministry of Education in a sense of seeing art not only as a discipline, but as a knowledge field.

With the curriculum parameters of 1998, the Art as a knowledge field next to science, and it started to have an important place in Brazilian legislation. The legislation shows that

It is the school's role to establish relations among the school knowledge about art and the production ways as well as the use of that knowledge in society. So, an art teaching and learning that happen in a creative way may contribute in order to have knowing as something to wonder oneself, have fun, and play with the unknown (1998, p. 31).

Not only that, but also the opposite; it is the act of wondering oneself, having fun, playing with the unknown as knowledge learned in a creative way and capable of stimulating the creative skill of the student. It would take him/her to unusual discoveries, which are able to be "used" in a way to contribute to the advance and dissemination of knowledge in society.

The National Curriculum Parameters do not differ of the art teaching in childhood education, due to the fact that officially to the Ministry of Education, the artistic education starts in elementary school. Although, that "omission" do not suppress the pedagogical action of art teaching in childhood and elementary school. To the Curriculum Parameters "the knowledge process comes from meanings that are formed from perception of the quality of lines, textures, colors, sounds, movements, subjects which are presented and/or built in the relation between work and receiver” (1998, p. 32). That “work” may be a musical writing, a corporal expression, a literary work, a statue, a painted or drawn image, because the artistic expressions are closely connected to the work author's or receiver's perceptions. The art teaching touches emotions, feelings; the children's, teenager's, young's, adult's perceptive capability. So, when the work of art is apprehended, then its content uptaking happens in mind in form of messages, and communication.

That's why the National Curriculum Parameters express the meaning of educational contact with art the following way:

By being part of the art universe, the students can finally know: 1) the artistic creation as a poetic experience (the technique and the creation as the articulation of meanings, as well as the materials, holders and several instrumentations experimentations); 2) the artistic creation as potentialities development: perception, reflection, investigation, sensitivity, imagination, curiosity and flexibility; 3) the artistic creation as an experience of human communication and group interactions in community, locally and in the cultures; 4) the artistic work as a signal form (its structure and organization); 5) the work of art as cultural production (document of human imaginary, his history and diversity) (Brazil, 1998: p. 37)

When the National Curriculum Parameters defend the art teaching in school, they relate art and culture by the aesthetic perception when affirm that

Learning art does not involve only an artistic production by the students, but also understanding what they do and what other do for the development of aesthetic perception in the contact with the artistic event seen as a cultural object of human history and as a group of relations. It is important that the students understand the meaning of artistic creation; they understand that their experiences of drawing, singing, dancing, filming or acting are not activity that aim to distract them from the relevance of other areas. It is known that by creating and knowing art, the student permeates the trajectory of learning that provides specific knowledges about his/her relation with the world. Besides that, they develop potentialities (such as perception, observation, imagination, and sensitivity) that can contribute to the conscience of their place in the world, as well as understanding other areas of the curriculum (BRASIL, 1998, p. 43) 


\section{Art and Education: The Teaching of Children by Images}

Ana Mae Barbosa (1994) defends the idea that the term "art-education” should be left out and in its place should be used art teaching and art learning. So, in her opinion, "teaching should be conceptually revised in elementary school, in universities, in technical school, museums, cultural centers and be taken in consideration in polytechnic projects" (p. 7). That is because the art-education is "an art epistemology, so it is the investigation of the ways of learning in school" (p. 7). It has a direct relation with art teachers' formation in order to assure that it does not have only the necessary sensitivity to listen, see and feel the artistic expressions to introduce them to children through dialogue, but also that they know how to use proper methodologies to art as knowledge and in the proper level of teaching in which it is taught. In that sense, in childhood education, which has as one of its more important tasks the one to give-a-voice-to-the-ones-who-do-not-have-it (the infant), meaning take him/her to Express himself/herself orally, as well as using gestures, drawings, and writing (mainly when it related to children who are Five years old), would contribute to the formation of inventive, creative, innovative, dreaming (in the sense that Paulo Freire takes the meaning of the word) humans by art teaching.

That way, the child is being prepared to rescue the "poiesis" within that will be there during the rest of life. The poiesis is taken as the imagination, creation, invention capability through different languages, mainly through the artistic imaginery language.

Ana Mae Barbosa in the above mentioned work uses the book by Jean Lipman and Richard Marshall, Art about art, 1978 edition to say what it is needed to be Said, which is convincing the art teachers or art-educators that

If the artist uses other artists' images, we do not have the right to take them away from children; if we prepare them to read the images created by artists, we are preparing them to read the images that are around their environment; the pure perception of a child without the influence of images is absent, since it is proved that $82 \%$ of our informal knowledge comes from images; in artistic learning, the mimesis is present as a similarity search (Greek sense) and not as a copy (Roman sense). (Barbosa, 1994: p. 21)

The above quotation tries to show to relevance of art teaching to children, mainly by the use of images. Those images are understood by children and are expressed in a mimetic form (mimesen), as a similarity, by giving them their own meaning. That is why it is not a pure and simple copy what the child is expressing, but an image that when it is understood by him/her, it goes through an understanding filter, and when he/she reproduces it, the child gives the image a another meaning, which is the one that has to do with his/her view of the world

At the same time, the image stimulates the child's imagination (image-imagination) making him/her be taken to an images world, as well as make him/her bring the images world to his/her own reality. In that process, the memory itself is activated and develops, because the memory is the ability to remember images in several levels of living (Read, 1958: p. 55). Therefore, the image remains in the child's memory for a longer time than oral words, stimulating him/her to remember not only the image, but its meaning, what it represents.

Herbert Read (1958) in the analyzed work mentions a comment from Gordon W. Allport who wrote it with the title Eidetic Imagery showing the relevance of image in pedagogical work:

The importance given to the pedagogical work, the emphasis that is given to it, and the hopes that are around it are always considered by the plasticity level and educational level that the psychical organization must have. It has always been correctly understood that the most relevant psychical happenings may be easily influenced, even though it is difficult to do it with the most elementary ones. The plastic nature of the psychic was supposed to have started only in the perceptual range. The new conclusions about the perception structure show that the range in which human nature is "plastic" is wider than even the most optimistic wanted to admit. (Read, 1958: p. 66)

Those observations are closely related with the fact that pedagogical technologies make use of images to teach and learn, because images are not abstract elements; they are concrete. Jean-Jacques Rousseau (1992) in the work Emilio or Education warns: "Never show a child something that he/she cannot see". The same way, according to Read (1958, p. 67), Dewey defends the idea of the "relevance of images to the educational development of a child”.

Herbert Read discusses in a subchapter of the work in reference to the images relevance to the development 
and the processes of thought of a grown up and a child. Based on the articles of two British psychologists, F. Aveling and F.C. Bartlett in the British Journal of Psychology, Herbert Head agrees with their conclusions about the importance of image use to stimulate the processes of thought. According to the author, professor Aveling concludes that "the images that best assures the 'individual' thought is the direct image of what is noticed", and reproducing professor Bartlett writes: "It is evident that I consider the image as being relevant in the process of thought. I would go further and say that images should be more and more used in thinking process, since the form of thinking receives genuine material to work with" (Read, 1958: p. 69). And quoting an excerpt of the work by Francis Galton, Inquiries into Human Faculty and its Development (London, 1907) writes: "A visual image (our highlighting) is the most perfect form of mental representation regardless of where it is the form, position and the relation of the objects in the space... Our free and full of word education has the tendency to repress this precious gift of nature", and concludes: "The faculty that is most important in all the technical and artistic occupations, that makes our generalizations fair die for lack of use, instead of being wisely cultivated in a way to be taken the best of it.” (Read, 1958: p. 71).

But Herbert Read goes even further to defend a privileged place where the image must take place in art teaching. According to him

The perceptions have as results images, sensations have as results feelings. They are the basic elements which we build our conception of the world and our behavior in the world. While the education goal is help the child in those learning and maturation processes, the matter is knowing IF our educational methods are appropriate to that goa... the use of image can help the child to develop his/her sensory-motor basis. (Read, 1958: p. 75)

The researched authors which discussed about the art/education subject and art teaching are unanimous in defending the image reading, the sound hearing, the feeling of things as fundamental to the mental development of children and to stimulate not only the thinking processes, but also to their own cognitive capability. In that sense, the inclusion of art/education in the National Curriculum Parameters of elementary school as a discipline instead of being an educational activity and also as a knowledge area is an important step to challenge teachers to stimulate the perceptive capability of the children through artistic expressions.

\section{From Comenius to Paulo Freire: Educating and Alphabetizing through Image}

We would like to affirm the relevance of the use of imagery art not only as part of a discipline that must be taught, but as an a didactic-pedagogic tool in the alphabetization of preschool and elementary school, by asking the teacher to go beyond the "ovenbird" which artistically builds the "existence house", and instead of becoming the educator/artist/architect that makes from imagery art a way to alphabetize by educating and educate by alphabetizing, building with the children the knowledge house. In that case, it is not about teaching art, but about teaching though art, by making from the dialogue a methodology and from the image a pedagogical tool which is similar to the one suggested by Johan Amos Comenios in his work Orbis sensualium pictus, de 1642. He said that everything must be based on a "world of things, images and writing" (Comenios, 1659: p. 1). In that work the author complements the Didactica Magna, by trying to show that it is possible to alphabetize and from that on "teach everybody everything" using the image and the image spelling in order to let the children (and the illiterate adult) learn how to read by writing and write by reading. The words are dialogue generators between the one who teaches, the one who learns, and the one who learns and teaches, making it possible to understand the meaning of the word. That way, the learner becomes conscious of the world of things and of men and realizes the sense of things and men. According to Johan Amos Comenios "the image and the written name of all things" allow men to leave ignorance of things and start to be conscious of the word around (Comenios, 1659: p. 1).

Therefore, it is not by chance that Pestalozzi presents in his work of 1802, Cómo gertrudis enseña a sus hijos not only the inductive method, but also stimulates the teaching through the lessons of things. Things teach and their images do, too.

We should remember that in 1799, Pestalozzi was sent to Stanz village, canton of Unterwalden in Switzerland, where the Helvetic Republic had just been proclaimed and hard received the French reaction. It destroyed the Canton, leaving between two hundred and thirty and two hundred and forty-seven abandoned children, according to Pestalozzi" (Pestalozzi, 1929: p. 7). Pestalozzi had the challenge of finding himself alone to develop "the task of educating", because "the number of children that went to school increase little by little until they were 
eighty with different ages, some of them were full of hope, some of them were used to begging, completely ignorant. What a task to educate them! Developing the education of those children, what a problem to solve!" (Petalozzi, 1980). That way, in the letters sent to Gessner by Pestalozzi, there was an educational action "report" that he had developed in Stanz. His initial ignorance on how to use the pedagogical practical and the educational work that was growing little by little, with method, rigor and joy. He acted through dialogue and lessons of things showing as an example "things" that were presented by nature, challenging some children to help each other in an anticipation of the mutual teaching method of Joseph Lancaster. But what called his attention the most was the fact that by lessons of things and the image presentation of "things", "I learned from them-I would be blind if I didn't - the natural relation that must be established among the natural knowledge of words. But I learned that unlimited trust in word-and-action damages learning, because the words become sounds and noises” (Idem, 1929: p. 9). Pestalozzi even says when refers to literacy methodology:

I was quickly forced to set aside the biggest childhood torture, the unfortunate letters; children wanted images and objects (things), and they could get quickly to express with perfection using that new method about the objects that were in their knowledge range. And the children found on the streets, on the yards, squares opportunities to apply their knowledge. (Pestalozzi, 1980: p. 17)

We could add one more quotation of that work by Pestalozzi to show the relevance given by him to the use of imagery art in the pedagogical action. He says: "I understood the importance of the use of drawings that should anticipate the alphabet; well chosen and distributed drawings, which were able to express the ideas that one wants to communicate through the language" (Pestalozzi, 1980). That view of the pedagogical practice with children does not make Pestalozzi only closer to Comenios and his Orbis sensualium pictus, but also "restarts and proceeds that work", like says the translator of the book Cómo gertrudis enseña sus hijos, José Tadeo Sepúlveda.

Paulo Freire, successor of Comenios and Pestalozzi, believes that it is necessary that the illiterate learns first how to do the reading of the world, and then develop the reading of the word. But is it possible to do the reading of the world? It is done through the images that are emerging. The path goes from the image towards the word and from there; it goes back to the image.

When Paulo Freire was to start his work of alphabetization/awareness, he tells in the book Pedagogy of indignation (2000) that the visual artist Francisco Brenand from Pernambuco created to him a set of ten "situations" that should be worked by him when preparing the cultural agents:

There were ten concrete situations, codifications as I call them, whose "reading" makes possible a discovering start of the human cultural activity. It was Francisco Brenand, brilliant Brazilian artist, great painter as well as potter, who made them by my request. To tell the truth, it was Ariano Suassuna who told me: "You need to talk to Brenand. I can already see the beauty of his work painting the different situations you need to challenge the agents in the discussion about culture”. (Freire, 2000: p. 96)

So, the cultural agents would be prepared initially through images. It was the imagery art working for education as a didactic-pedagogic tool to make the cultural agents learn how to do the reading of the world. They would certainly reproduce that form of teaching to the illiterate.

Paulo Freire was an enthusiastic of the "beauties" of the world, loved the aesthetic, and of course, the artistic expressions. In his view, curiosity stimulated by image, by the artistic beauty would make the learners "feel" educated because "we can make that do", they would say, "pointing to a clay jar painted in a picture", attests Paulo Freire (Freire, 1992: p. 99).

Carlos Lyra in his book The forty hours of angicos: a pioneer experience in education (1996) says that when Paulo Freire used images to alphabetize, he had as a goal to make it clear to the illiterate the concepts of culture and nature. That way, culture would be "like a contribution that the man makes to the world he didn't create. The culture as a result of his work and his creator and recreator effort. The man, at last, in the world and with the world as a subject, not an object” (Lyra, 1996: p. 24).

If Paulo Freire alphabetization methodology was initially made to young people and adults, it does not mean that it cannot be used in children's alphabetization, offering them the opportunity of being conscious about themselves and the world from the beginning of the process. So, by following the steps of Comenius and Pestalozzi, the imagery art should be used as an element capable of turning the alphabetization process easier and deeper by the impression the children have of things. 


\section{Final Considerations}

As we have just showed in this article, our research was developed so far, by trying to find in the adequate bibliography, historical and theoretical elements that are able to give the researchers scientific data that is needed to move to the second step of the investigation. It will happen by going to the teaching institutions, not only to observe the pedagogical action of childhood and elementary education teachers of the school in Curitiba, but also acting through participative observation. Because if we have the necessary theory and the experiences made by educators such as Comenios and Pestalozzi, we are able to show that both theoretically and in practice, Paulo Freire's methodology of adult alphabetization can also be successfully used in the alphabetization of children of the first two teaching levels: Preschool and elementary.

\section{References}

Agamben, G. (2005). Childhood and History: The Destruction of Experience and Source of History. Belo Horizonte: UFMG. Aristotle (2005). Metaphysics. São Paulo: Loyola.

Barbosa, A. M. (1994). The image in Art Education. São Paulo: Editora Perspectiva.

Brazil (1998). National Curriculum Standards, Art. Brasília: MEC.

Comenios, J. A. (1659). Orbis Sensualium Pictus. London: Printed for J. Kirton, at the Kings Arms.

Freire, P. (1992). Pedagogy of the Hope. São Paulo: Paz e Terra.

Freire, P. (2000). Pedagogy of the Indignation. São Paulo: Unesp.

Macedo, L. (1994). Constructivist Essays. São Paulo: Casa do Psicólogo.

Pestalozzi, J. H. (1929). As Gertrude Teaches Her Children. Peruggia: La Nuova Italia.

Piaget, J. (1986). The Language and Thought of the Child. São Paulo: Martins Fontes.

Read, H. E. (1958). Education through Art. São Paulo: Martins Fontes.

Rousseau, J.-J. (1992). Emilio or the Education. Rio de Janeiro: Bertrand Brasil. 